\title{
Discriminated response patterning in goldfish with successive presentation and explicitly unpaired pseudoconditioning procedures
}

\author{
D. J. ZERBOLIO and L. L. WICKSTRA \\ University of Missouri, St. Louis, Missouri 63121
}

\begin{abstract}
Goldfish show discriminated responding by shuttling in increasingly more US paired time frames than unpaired time frames both for the successive-presentation and explicitly unpaired pseudoconditioning procedures, where measurement, in addition to the CS, is made in a comparable period of the intertrial interval just prior to the US. These data strongly question stimulus-specific interpretations of response patterns arising from the use of the successivepresentation procedure, suggest that goldfish learn a conditioned inhibition to an unpaired stimulus, and may imply that the explicitly unpaired pseudoconditioning procedure is an appropriate control, in goldfish, for the successive-presentation procedure.
\end{abstract}

With successive presentation of two cues, where one $\left(\mathrm{S}^{\mathrm{d}}\right)$ is classically paired with a shock US and where the second $\left(\mathrm{S}^{\Delta}\right)$ is not US paired, Woodard and Bitterman (1971) showed that goldfish responded differentially on more $S^{d}$ than $S^{\Delta}$ trials. This discriminated performance occurred despite the fact that the subjects response neither terminated the cue signal nor, in the $S^{d}$ case, produced US omission. The results were viewed as evidence for classical conditioning of a discriminated response. The present study is an attempt to replicate the basic finding and to examine other stimulus/response conditions shown to affect shock-motivated performance in goldfish. The conditions compared are responsecontingent US omission, $\mathbf{S}^{\mathrm{d}}$ termination, $\mathrm{S}^{\mathbf{A}}$ termination, and intertrial-interval (ITI) illumination, all of which have affected shuttlebox performance in single-stimulus procedures (Scobie \& Fallon, 1974; Zerbolio \& Wickstra, 1978a, 1978b).

\section{EXPERIMENT 1}

\section{Method}

Subjects. One hundred and twentyeight goldfish, $5-6 \mathrm{~cm}$ long and housed as described earlier (Zerbolio \& Wickstra, $1978 \mathrm{a}, 1978 \mathrm{~b})$, served as subjects.

Apparatus. Four identical shuttleboxes, described in detail earlier (Zerbolio \& Wickstra, 1978a, 1978b), were used. The $S^{d}$ and $S^{\Delta}$ stimuli were blue or red illumination provided by 7-W $110-\mathrm{V}$ ac Christmas tree lamps, comparable to those described by Woodard and Bitterman (1971). For half of the subjects, the ITI was illuminated with a green $7-\mathrm{W} 110-\mathrm{V}$ ac lamp. Illumination (either $\mathrm{S}^{\mathrm{d}}, \mathrm{S}^{\boldsymbol{\Delta}}$, or ITI) occurred simultaneously at both tank ends as appropriate. The US, delivered via stainless steel plates lining the interior side walls, was a single $200-\mathrm{msec} 7.5-\mathrm{V}$ ac shock $(.656 \mathrm{~V} / \mathrm{cm})$, which has been shown to be sufficient to produce avoidance behavior in this apparatus (Zerbolio \& Wickstra, 1975). All events were programmed and recorded by appropriate circuitry.

Procedure. A factorial arrangement of 2 procedures each for $\mathrm{Sd}, \mathrm{S}^{\Delta}$, and US presentation (classical or instrumental) plus
2 levels of ITI illumination constituted 16 groups of 8 subjects each, run for $30 \mathrm{Sd}^{\mathrm{d}}$ and $30 \mathrm{~S}^{\Delta}$ trials a day in Gellerman series, with a variable-interval (VI) 60-sec ITI, for 7 consecutive days. For the classical procedure, termination of cue ( $S^{d}$ and/or $S^{\Delta}$ ) or omission of the US could not occur ( $\left.S^{d} n c, S^{\Delta} n c, U S n c\right)$. For the instrumental procedure, termination of cue $\left(S^{d}\right.$ and/or $\left.S^{\Delta}\right)$ or omission of the US was contingent upon the subjects response $\left(S^{d_{c}}, S^{\Delta} c, U S c\right)$ in the appropriate cue time frame. The ITI was either illuminated with green lamps or dark (not illuminated). Half of each group had a red $S^{d}$ and blue $S^{\Delta}$ (reversed with the remainder). A trial consisted of a $10-\mathrm{sec}$ stimulus presentation ( $S^{d}$ or $S^{\Delta}$ ) that was monitored for response. If appropriate, because of procedure or failure of the subject to respond, the US was presented at the end of the $S^{d}$ cue period but was never paired with the $S^{\Delta}$ cue. Only the initial response in any 10 -sec measurement period was recorded as a response.

\section{Results and Discussion}

Red/blue cue color differences did not differ in preliminary analyses, so the data were combined for further analysis. Five-way analyses using the $2 \mathrm{~S}^{\mathrm{d}}, 2 \mathrm{~S}^{\mathbf{\Delta}}, 2 \mathrm{US}$, and 2 ITI illumination conditions, over 7 days of training as factors for the number of $S^{d}$ trials with response, $S^{\Delta}$ trials, and $S^{d}-S^{\Delta}$ differences were calculated.

The number of $S^{d}$ trials with response increased markedly with training $[\mathrm{F}(6,672)=334.208, \mathrm{p}<.01$, $\omega^{2}=.458$ ] and reliably faster when $S^{d}$ could be terminated contingent on the subjects response $\left(\mathrm{S}^{d} \mathrm{c}\right)$ than when the subject's response did not result in $S^{d}$ termination $\left(S^{d} n c\right)\left[F(1,112)=19.825, p<.01, \omega^{2}=.043\right]$.

The number of $S^{\Delta}$ trials with response showed a small but reliable change with training $[F(6,672)=4.602$, $\left.\mathrm{p}<.05, \omega^{2}=.012\right]$. Figure 1 shows both $\mathrm{S}^{\mathrm{d}}$ and $\mathrm{S}^{\Delta}$ response means over days of training in the left panel.

An analysis of $S^{d}-S^{\Delta}$ showed subjects responded on an increasingly larger number of $S^{d}$ trials with training $\left[F(6,672)=254.32, p<.01, \omega^{2}=.419\right]$, with faster increases when the subject could terminate the $\mathrm{S}^{\mathrm{d}}$ $\left(S^{d} c\right)$ than when it could not $\left(S^{d} n c\right)[F(1,112)=14.477$, $\left.\mathrm{p}<.01, \omega^{2}=.034\right]$. These data are shown in the right 


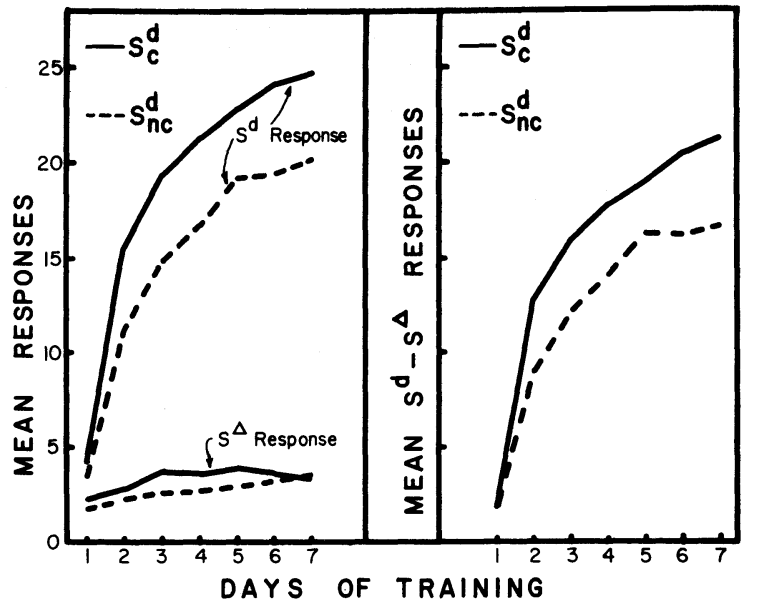

Figure 1. The mean response over days for subjects able to terminate the $S^{d}\left(S^{d} c\right)$ and those unable to terminate it $\left(S^{d} n c\right)$. Also, the means for $S^{d}-S^{\Delta}$, which would be expected to show no increase if the subject was not discriminatively responding, are shown in the second panel.

panel of Figure 1. No other variables produced reliable effects.

The data are very similar to those reported by Woodard and Bitterman (1971). The surprising finding is no differential effect for US omission or ITI illumination, variables shown to affect single-cue avoidance (Scobie \& Fallon, 1974; Zerbolio \& Wickstra, 1978a, $1978 \mathrm{~b})$. But the data are consistent with those reported by Woodard and Bitterman (1973) in single-stimulus procedures. One might conclude from the data that goldfish can learn an $\mathrm{S}^{\mathrm{d}} / \mathrm{S}^{\boldsymbol{\Lambda}}$ response discrimination independent of the mode of US administration. But there is a potential alternative explanation. Consider the particular form of the successive-presentation procedure used: $S^{\mathbf{A}}$ is never paired with the US and $S^{d}$ (potentially) is always paired. Essentially, one stimulus is never paired with the US, a striking parallel to the explicity unpaired pseudocondition (EUPC) procedure. This parallel is shown graphically in Figure 2 .

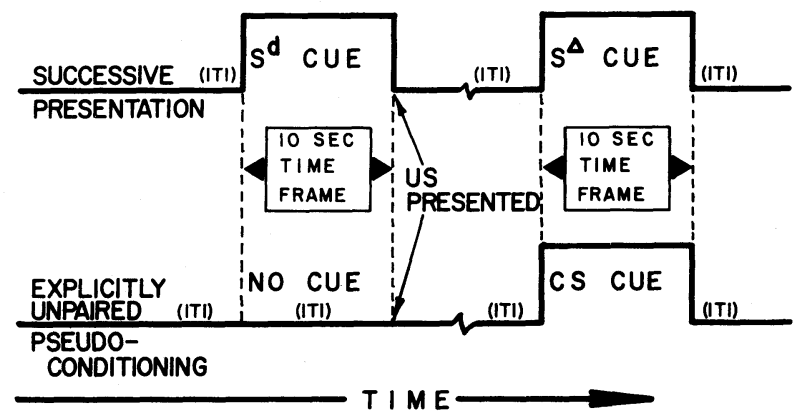

Figure 2. The comparison between the form of successive presentation used and the explicitly unpaired pseudoconditioning procedures showing the striking similarity between the two if measurement is made in equivalent time frames.
Notice that conclusions involving discriminated response acquisition require the subject to respond in more $S^{d}$ time frames than $S^{\boldsymbol{\Lambda}}$ time frames. Earlier work has shown that, in the EUPC procedure, CS response rates are low and thus comparable to the $S^{\Delta}$ response rates of Experiment 1. The remaining question is whether goldfish respond more often in the 10 -sec time frame prior to the US than in the unpaired CS time frame when run with EUPC procedures. Earlier work (Steiner, 1971; Zerbolio \& Wickstra, 1978a, 1978b) suggest they might.

A second experiment was run to examine this possibility.

\section{EXPERIMENT 2}

\section{Method}

Subjects. Sixty-four 5- to 6-cm goldfish from the same source and housed as in Experiment 1 served as subjects.

Apparatus. The apparatus was the same as that in Experiment 1.

Procedure. Eight groups of eight subjects each in a factorial arrangement of 2 ITI illumination (green ITI or no ITI illumination), 2 CS termination (CS terminated with subject's response or no CS termination), and 2 US omission conditions (US omitted by a response within the $10 \mathrm{sec}$ prior to its presentation or no US omission) were run for 7 consecutive days. Each day, $60 \mathrm{CS}$ and 60 US presentations were administered in a Gellerman series, constituting 120 total stimuli with VI 30-sec interstimulus (ISI) interval. The CS was a 10-sec presentation of illumination different from the ITI (red for half of each group, blue for the remainder), which was an increase in illumination for those subjects with no ITI illumination and a color change from green for the remainder. A single $200-\mathrm{msec} 7.5-\mathrm{V}$ ac $(.656 \mathrm{~V} / \mathrm{cm})$ shock served as the US. A total of 12010 -sec time frames were monitored for shuttle response, 60 filled with the CS but not paired with the US and 60 just prior to the US presentation time during the ITI.

\section{Results and Discussion}

The preliminary analysis showed no CS color differences (red vs. blue). Analysis of the number of CS time frames and number of pre-US time frames in which at least one shuttle response occurred showed similar patterns of results. An increase in response with training was found during both the CS 10-sec time frame $\left[F(6,336)=15.908, \quad p<.01, \omega^{2}=.067\right]$ and the pre-US time frame $\left[\mathrm{F}(6,336)=69.438, \mathrm{p}<.01, \omega^{2}=\right.$ $.250]$. Additionally, when the subject could omit the US with a pre-US time frame response, it responded in more CS time frames $[\mathrm{F}(1,56)=10.309, \mathrm{p}<.01$, $\left.\omega^{2}=.078\right]$ and pre-US time frames $[\mathrm{F}(1,56)=6.866$, $\left.\mathrm{p}<.05, \omega^{2}=.053\right]$. Confirming this is the interaction of Training by US Contingency for both the CS time frames $\left[F(6,336)=8.082, p<.01, \omega^{2}=.032\right]$ and the pre-US time frame data $[F(6,335)=8.177, p<.01$, $\left.\omega^{2}=.026\right]$. These results are clearly shown in the left panel of Figure 3.

If subjects are responding in more pre-US $10-\mathrm{sec}$ time frames than CS time frames, a pre-US - CS response difference, like the $S^{d}-S^{\Delta}$ response difference 


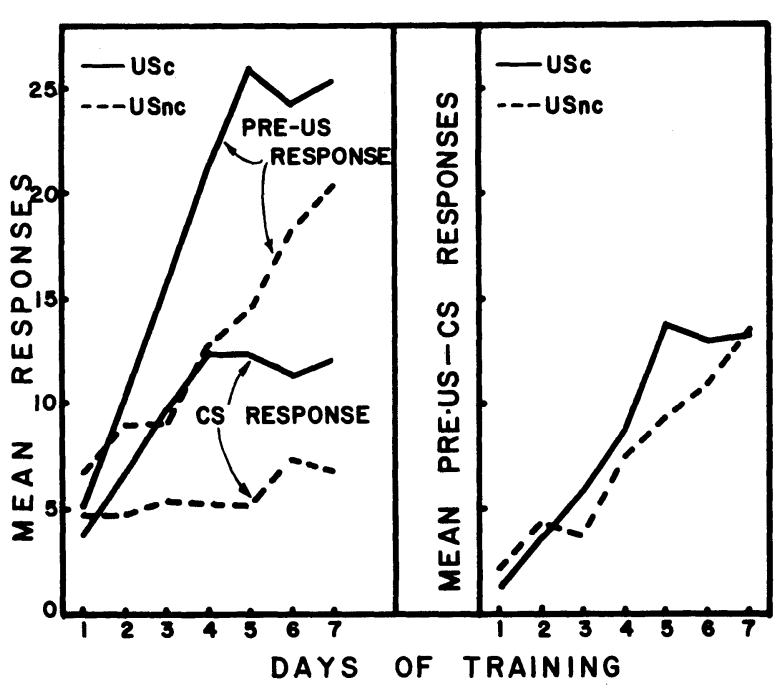

Figure 3. The mean responses over days for subjects able to omit the US(USc) and those unable to produce US omission (USnc) for both CS and pre-US periods. Also, pre-US - CS response rates, which would be expected to show no increase if the subject was not discriminatively responding, are shown in the second panel.

in Experiment 1, would be expected to yield a reliable positive effect. That is precisely what was found. On average, subjects responded increasingly more often in the pre-US time frame than the CS time frame with training $\left[F(6,336)=49.068, p<.01, \omega^{2}=.338\right]$, with no difference shown for US contingency. Of course, the pre-US period, which occurs randomly (Gellerman series and VI $60 \mathrm{sec}$ ) throughout the ITI cannot be distinguished from the ITI. Yet these animals showed a discriminated response pattern between a cued, but unpaired, 10-sec time frame (the CS) and an uncued, but paired, 10-sec portion of the ITI. One expects a discriminated response pattern with differential cues ( $S^{d}$ and $S^{\Delta}$ ) but does not with a cue and no cue (CS and a portion of the ITI). But Experiment 2 differs from Experiment 1 by more than just the $S^{d}$ omission. In Experiment 1 , there were $30 \mathrm{~S}^{\mathbf{\Lambda}}$ and $\mathrm{S}^{\mathrm{d}}$ with US presentations per day, constituting 60 10-sec time frames measured for response and 30 US presentations. In Experiment 2, there were $60 \mathrm{CS}$ and 60 pre-US with US presentations per day constituting 12010 -sec time frames measured for response and 60 US presentations. Thus, the shock density and measurement time frame density in Experiment 2 were twice that of Experiment 1, with half of the time between measurement periods. The twofold increase in US and/or measurement time frame density may have contributed to a higher overall ITI response rate and spuriously inflated the probability of response during the ITI, and thus the pre-US portion measured for response. A third experiment was conducted where the number of measurement time frames ( $30 \mathrm{CS}$ and 30 pre-US) and US presentation (30) were identical to that in Experiment 1. Since the discrimination index of pre-US - CS responses did not differ as a function of US-contingent omission, only the EUPC condition was run.

\section{EXPERIMENT 3}

\section{Method}

Subjects. Sixteen 5- to 6-cm goldfish, from the same source and housed as before served as subjects.

Apparatus. The apparatus was the same as that in the previous experiments.

Procedure. Two groups of eight subjects each, one with an illuminated ITI (green) and the other with no ITI illumination, were given $30 \mathrm{CS}$ and 30 US presentations per day in Gellerman series, with a VI $60-\mathrm{sec}$ ISI, for 7 consecutive days using and EUPC procedure. Half of each group had a red CS, the remainder a blue CS. The 10 -sec CS time frame and a 10 -sec period of the ITI just prior to the US (pre-US) were measured for response. All other details were comparable to the previous experiments.

\section{Results and Discussion}

Preliminary analyses indicated no differences due to CS color and no effect due to differential ITI illumination. The analysis of the number of time frames per day with at least one shuttle response showed no change with training for the CS time frame $(\mathrm{F}<1)$ but an increase in the number of pre-US time frames with response with training $[\mathrm{F}(6,84)=14.366, \mathrm{p}<.01$, $\left.\omega^{2}=.205\right]$ was found. These data are shown in the left panel of Figure 4. Given the number of time frames in which a response occurred for both pre-US and CS periods, the analysis of pre-US - CS responses showed this difference increased with training $[F(6,84)=10.913$, $\left.\mathrm{p}<.01, \omega^{2}=.235\right]$, indicating that, with training, goldfish responded increasingly more often in the pre-US time frames than in the CS time frames. Thus, these data clearly show differential response patterning. In fact, subjects in all three experiments responded in

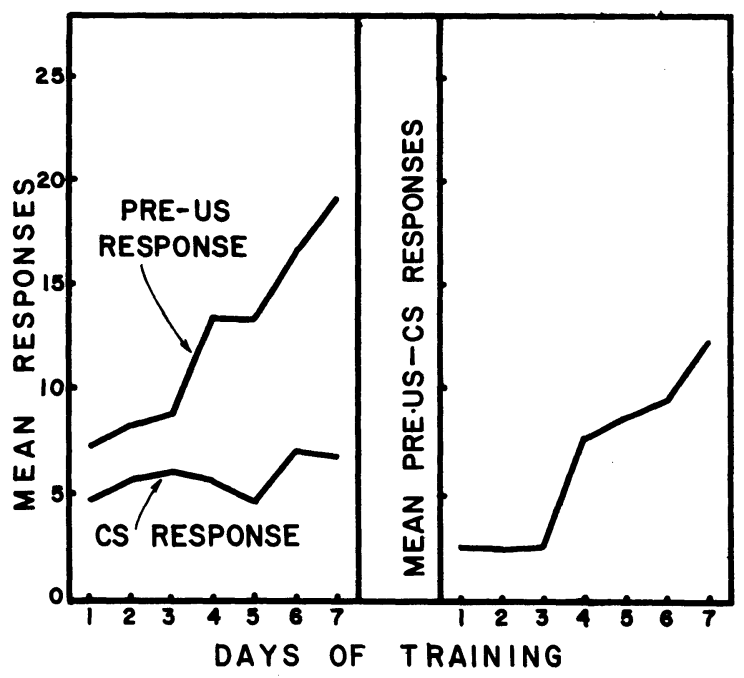

Figure 4. The mean responses over days for pre-US and CS periods are shown in the left panel and the pre-US - CS rates, which would be expected to show no increase unless the subject was discriminatively responding, are shown in the right panel. 
increasingly more US paired time frames than unpaired time frames. Since this discriminated response pattern occurred with (Experiment 1) or without (Experiments 2 and 3) a specific stimulus distinguishing the US paired time frame from the rest of the ITI, the stimulus specificity of a response occurring in the US paired time frame seems questionable. Further, since the $S^{d}$ stimulus may be, in part, superfluous, response consequences such as $\mathrm{S}^{\mathrm{d}}$ termination and/or US omission associated with the $S^{d}$ are very difficult to interpret. Obviously, the contribution of EUPC to the discriminated patterning of results obtained in Experiment 1 with successivepresentation procedures must be determined before clear interpretations of those data are possible. Additionally, the present failure to find effects due to the manipulation of variables shown in previous singlestimulus work to have effects (such as the ITI illumination variable) can be viewed as consistent with the earlier work where, either with or without ITI illumination, CS response rates in EUPC procedures produce low response rates (Zerbolio \& Wickstra, 1978a, 1978b). If any conclusion can be drawn from Experiments 2 and 3, aside from questioning any stimulus-specific interpretation of results from the successive-presentation procedure as used in Experiment 1, it is that the consistently lower response incidence in the unpaired time frame associated with a specific cue ( $\mathrm{S}^{\Delta}$ or $\mathrm{CS}$ ) may represent a conditioned inhibition to the CS cue in an EUPC design, as suggested by Rescorla (1967).

In sum, then, the similar response patterns during US paired and unpaired time frames, both in successivepresentation and EUPC procedures, strongly question the stimulus specificity of the discriminated response pattern, especially for the US paired stimulus. It may be that the EUPC procedure is, for goldfish, the appropriate control procedure for the successive-presentation paradigm along with its typical use as one of the controls for single-stimulus avoidance paradigms.

\section{REFERENCES}

Rescorla, R. A. Pavlovian conditioning and its proper control procedures. Psychological Review, 1967, 74, 71-80.

Scobie, S. R., \& Fallon, D. Operant and Pavlovian control of a defensive shuttle response in goldfish (Carassius auratus). Journal of Comparative and Physiological Psychology, 1974, 86, 858-866.

STEINER, G. Stimulus control of avoidance learning in fish. Journal of Comparative and Physiological Psychology, 1971, 74, 52-58.

Woodard, W. T., \& BitTerman, M. E. Classical conditioning of goldfish in the shuttlebox. Behavior Research Methods \& Instrumentation, 1971, 3, 193-194.

Woodard, W. T., \& Bitterman, M. E. Pavlovian analysis of avoidance conditioning in the gold fish (Carassius auratus). Journal of Comparative and Physiological Psychology, 1973, 82, 123-129.

Zerbolio, D. J., \& Wickstra, L. L. The effect of power (US intensity $\mathrm{x}$ US duration) on shuttlebox avoidance acquisition in goldfish. Bulletin of the Psychonomic Society, 1975, 4, 345-347.

Zerbolio, D. J., \& Wickstra, L. L. Goldfish avoidance acquisition: Is the process classical, instrumental, or phototaxis? Bulletin of the Psychonomic Society, 1978, 11, 321-323. (a)

Zerbolio, D. J., \& Wickstra, L. L. Does elimination of a negative phototaxis eliminate CAR acquisition in goldfish? Bulletin of the Psychonomic Society, 1978, 11, 324-326. (b)

(Received for publication January $31,1979$. ) 